\title{
PENGARUH MODEL PROBLEM BASED LEARNING (PBL) TERHADAP HASIL BELAJAR FISIKA DI KELASX MIA SMA NEGERI 1 STABAT
}

\author{
Yenni Dwi Aprilita Sagala danUsler Simarmata \\ Jurusan Fisika FMIPA Universitas Negeri Medan \\ ysagala1@gmail.com
}

\begin{abstract}
ABSTRAK
Penelitian ini bertujuan untuk mengetahui pengaruh penerapan model problem based learning terhadap hasil belajar dan akivitas siswa. Jenis penelitian ini adalah quasi eksperiment dengan desain nonequivalent control group design dan dilakukan di SMA Negeri 1 Stabat tahun pelajaran 2014/2015. Sampel dipilih secara cluster random sampling, kelas X MIA-2 menggunakan model konvensional dan kelas X MIA-3 menggunakan model problem based learning. Hasil uji hipotesis adalah terdapat pengaruh model problem based terhadap hasil belajar fisika siswa. Hasil aktivitas siswa yang menggunakan model problem based learning termasuk kategori aktif.
\end{abstract}

Kata Kunci : model problem based learning, hasil belajar, aktivitas.

\begin{abstract}
The purpose of this study was to know the effects of problem based learning model on student's achievement and activity. Quasi experiment and nonequivalent control group design was used, in The First Senior High School in Stabat, school year 2014/2015, X MIA-2 class with conventional model and X MIA 3 class with problem based learning model, who were selected by cluster random sampling. The hypothesis was the application of problem based learning model could increase physics student's achievement. The activity shown student was used problem based learning model is active group.
\end{abstract}

Keywords : problem based learning model, achievement, activity.

\section{PENDAHULUAN}

Pendidikan adalah sebuah program yang melibatkan sejumlah komponen yang bekerja sama dalam mencapai tujuan yang diprogramkan, yaitu menjadikan manusia yang beriman dan berilmu. Tujuan tersebut dapat dicapai dalam kegiatan belajar mengajar yang dimuat dari hasil belajar siswa. Namun, hasil belajar fisika siswa SMA Negeri 1 Stabat belum memuaskan.

Siswa masih menganggap fisika sebagai mata pelajaran yang sulit dan dipenuhi rumus, proses belajar mengajar masih berpusat pada guru yang terlihat guru masih menggunakan pembelajaran konvensional dengan metode diskusi, tanya jawab, penugasan dan kurangnya memperhatikan pengetahan awal siswa. Hal ini menyebabkan siswa pasif sehingga hasi belajar fisika belum memuaskan.

Siswa berharap belajar fisika dapat dilakukan dengan praktikum sehingga terdapat variasi dalam proses belajar. Praktikum juga diharapkan dekat dengan kehidupan sehari-hari agar mudah dipahami siswa, sehingga menumbuhkan kreativitas dan meningkatkan potensi yang siswa miliki dan lebih mudah untuk memahami konsep yang dpelajari. 
Belajar adalah kegiatan manusia yang menjadi proses dalam mengubah tingkah laku sebagai hasil interaksinya dengan lingkungan melalui latihan secara kompleks. Hasil belajar adalah perubahan tingkah laku yang terjadi sebagai keluaran dari belajar. Belajar merupakan eksperimen, eksperimen berarti berbuat, berbuat berarti aktivitas, aktivtas belajar adalah aktivitas bersifat fisik maupun mental yang terkait selama belajar.

Berdasarkan teori tersebut maka pemilihan model yang baik, akan sangat membantu siswa dalam belajar. Karena dalam model pembelajaran dapat menjelaskan kegiatan pembelajaran berlangsung, dimulai dari awal hingga saat akhir pembelajaran, dan salah satu model yang ditawarkan adalah model problem based learning (PBL) untuk memenuhi harapan siswa.

Model PBL adalah pembelajaran yang penyampaiannya dilakukan dengan cara menyajikan suatu permasalahan, mengajukan pertanyaan-pertanyaan, memfasilitasi penyelidikan dan membuka dialog. Dengan kegiatan seperti ini maka, kegiatan proses belajar untuk perbekalan hidup. Melalui belajar maka pengetahuan yang dimiliki dapat digunakan untuk mengatasi masalahmasalah yang dihadapi yang mempengaruhi potensi siswa.

Berdasarkan penjelasan di atas untuk meningkatkan prestasi belajar fisika perlu digunakan model pembelajaran yang sesuai karakteristik materi dan karakteristik siswa. Dalam hal ini peneliti mencoba menerapkan pembelajaran fisika dengan model PBL untuk melihat hasil belajar dan aktivitas siswa.

Tujuan yang dicapai dalam penelitian ini adalah untuk mengetahui: (1) hasil belajar fisika dengan menggunakan model PBL, (2) hasil belajar fisika dengan menggunakan konvensional, dengan menggunakan model PBL, dan (4) apakah ada perbedaan akibat pengaruh model PBL terhadap hasil belajar fisika.

\section{METODE PENELITIAN}

Penelitian ini dilakukan di SMA Negeri 1 Stabat, pada tahun pelajaran 2014-2015. Penelitian ini termasuk dalam jenis penelitian quasi ekperiment.

Variabel penelitian ini ada dua yaitu variabel bebas untuk model PBL dan pembelajaran konvensional dan variabel terikat untuk hasil belajar siswa.

Populasi pada penelitian ini adalah siswa kelas X MIA SMA Negeri 1 Stabat tahun pelajaran 2014/2015 terdiri dari 6 kelas. Sampel pada penelitian ini diambil dengan teknik cluster random sampling, kelas yang menjadi sampel adalah X MIA-2 dan X MIA-3.

Penelitian menggunakan desain dengan nonequivalent control grup design, satu kelas diberi perlakuan dengan menggunakan model PBL seperti pada tabel 1 .

Tabel 1. Desain Penelitian (Sugiyono, 2013)

\begin{tabular}{|lccc|}
\hline Kelas & $\begin{array}{c}\text { Pre } \\
\text { tes }\end{array}$ & $\begin{array}{c}\text { Perla } \\
\text { kuan }\end{array}$ & $\begin{array}{c}\text { Pos } \\
\text { tes }\end{array}$ \\
\hline Eksperimen & $\mathrm{T}_{1}$ & $\mathrm{X}$ & $\mathrm{T}_{2}$ \\
Kontrol & $\mathrm{T}_{1}$ & & $\mathrm{~T}_{2}$ \\
\hline
\end{tabular}

Keterangan :

$\mathrm{T}_{1} \quad$ : Pemberian pretes

$\mathrm{T}_{2} \quad$ : Pemberian postes

$\mathrm{X}$ : Perlakuan dengan model PBL

Instrumen penelitian yang digunakan ada dua yaitu tes hasil belajar, dan lembar observer untuk mengamati aktivitas, afektif dan psikomotorik siswa.

Hipotesis dalam penelitian ini menggunakan uji beda (Uji-t). Teknik analisis yang digunakan untuk hasil observasi adalah kualitatif deskriptif, 
dimana hanya melukiskan aktivitas dari sampel yang menggunakan model PBL (Sudjana, 2009).

\section{HASIL DAN PEMBAHASAN \\ Hasil}

Berdasarkan tes hasil belajar yang telah dilakukan di SMA Negeri 1 Stabat diperoleh data pretes untuk kelas ekperimen 16,3 dan kelas kontrol sebesar 16,6. Secara ringkas data pretes ditunjukkan pada Gambar 1.

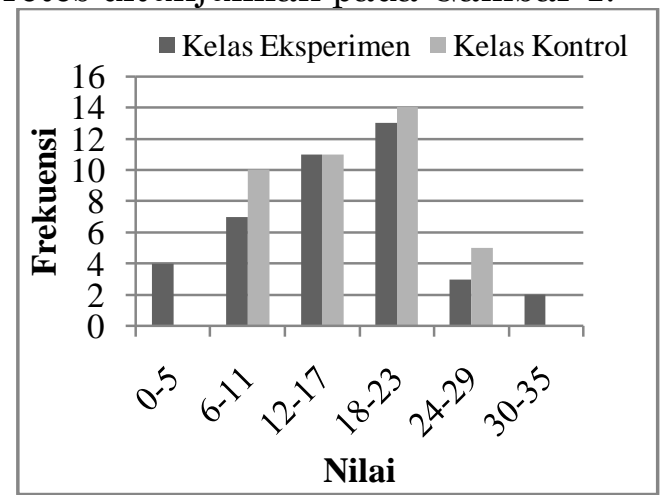

Gambar 1. Data Pretes Kelas Eksperimen dan Kontrol

Setelah diberi perlakuan pada kelas eksperimen dengan menggunakan model PBL diperoleh rata-rata postes sebesar 43,50 dan unuk kelas kontrol yang menggunakan pembelajaran konvensional adalah 33,35. Baik pada kelas eksperimen maupun kontrol siswa brjumlah 40 orang. Secara ringkas data postes ditunjukkan seperti pada Gambar 2.

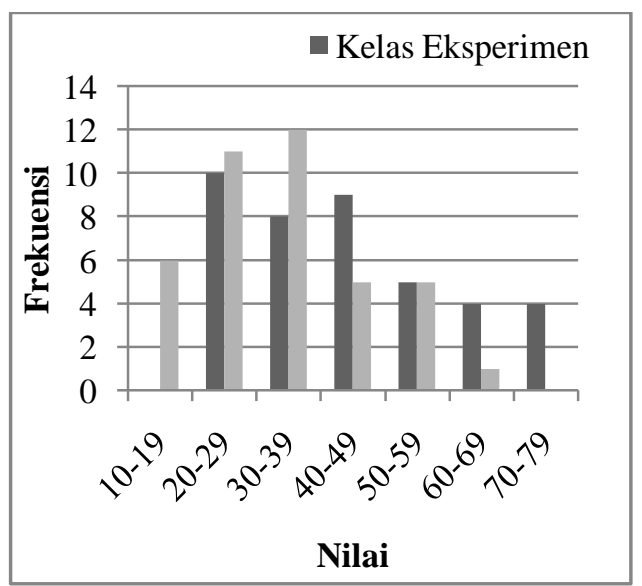

Gambar 2. Data Postes Kelas Eksperimen dan Kontrol
Observasi aktivitas dilakukan selama kegiatan belajar mengajar yang dilakukan selama 4 kali pertemuan pada kelas eksperimen. Hasil aktivitas ditunjukkan pada Gambar 3.

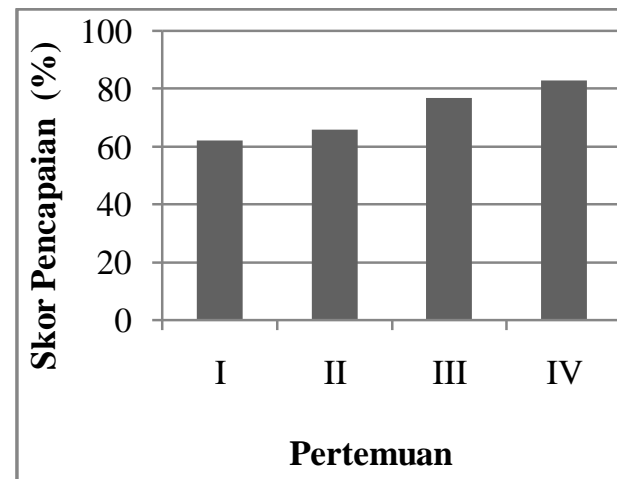

Gambar 3. Diagram Batang Data Aktivitas Kelas Eksperimen

Penilaian keterampilan (psikomotorik) dan sikap (afektif) siswa diamati setiap pertemuan selama proses belajar mengajar berlangsung dibantu oleh observer. Pengamatan dilakukan pada kelas eksperimen dan kelas kontrol. Adapun hasilnya ditunjukkan pada gambar 4 dan gambar 5 .

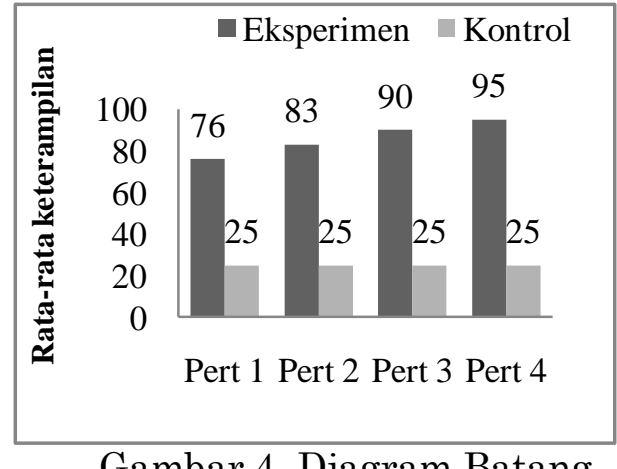

Keterampilan Kelas Eksperimen dan Kelas Kontrol 


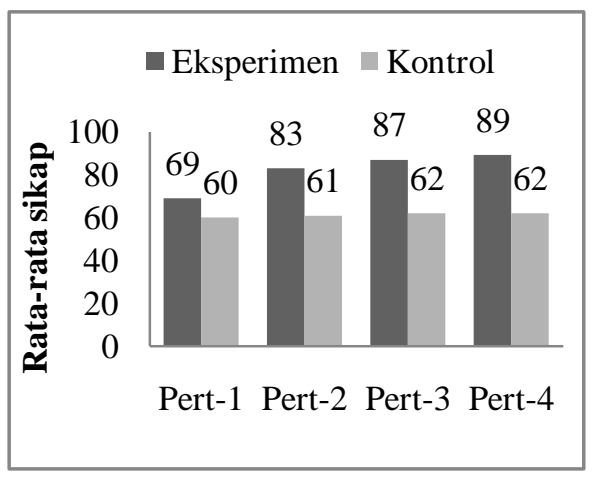

Gambar 5. Diagram Batang Sikap

Kelas Eksperimen dan Kelas Kontrol

\section{Pembahasan}

Hasil penelitian menunjukkan bahwa ada pengaruh yang signifikan model PBL terhadap hasil belajar fisika siswa pda materi Suhu dan Kalor di kelas X MIA Semester II SMA Negeri 1 Stabat. Hal ini ditunjukkan dengan adanya perbedaan peningkatan hasil belajar kelas eksperimen dengan nilai rata-rata pretes 16,3 dan postes 43,5 sedangkan pada kelas kontrol dengan nilai rata-rata pretes 16,6 dan posts dengan nilai rata-rata 33,35. Meskipun hasil postes masih di bawah KKM, namun pada kelas eksperimen mengalami peningkatan sebesar 27,2 dan pada kelas kontrol 16,7. Perbedaan ini disebabkan oleh beberapa faktor yaitu rendahnya pengetahuan awal siswa, baru pertama kali diterapkan model PBL, dan keterbatasan waktu yang dimiliki siswa. Demikian juga aktivitas siswa pada kelas eksperimen mengalami peningkatan yaitu pada pertemuan pertama sampai keempat berturut-turut adalah 62\%, 66\%, 77\% dan $83 \%$.

Penilaian keterampilan kelas eksperimen dan kelas kontrol memiliki perbedaan dimana rata-rata nilai keterampilan kelas kontrol dari pertemuan pertama sampai keempat adalah 25. Kriteria keterampilan pada kelas kontrol tergolong tidak mencapai, ini dikarenakan tidak dilaksanakannya praktikum. Sedangkan nilai rata-rata pada kelas eksperimen dari pertemuan pertama sampai pertemuan keempat berturut-turut adalah $76,83,90$, dan 95, ini tergolong baik sekali. Hal ini menunjukkan bahwa keterampilan kelas eksperimen yang menggunakan model PBL lebih baik dibanding kelas kontrol yang menggunakan pembelajaran konvensional. Sama halnya dengan keterampilan, penilaian sikap pada kelas eksperimen dengan kelas kontrol juga memiliki hasil yang berbeda-beda. Rata-rata sikap kelas eksperimen dari pertemuan pertama sampai pertemuan keempat berturutturut adalah 69, 83, 87, dan 89 juga termasuk dalam katgori baik sekali. Rata-rata sikap kelas kontrol pada setiap pertemuan adalah $60,61,62$, dan 62 yang tergolong dalam kriteria cukup. Hal ini juga menunjukkan kelas eksperimen yang menggunakan model PBL lebih baik dibanding kelas kontrol yang menggunakan pembelajaran konvensional.

Hasil belajar siswa di kelas eksperimen yang menggunakan model PBL menunjukkan hasil yang lebih baik dibandingkan kelas kontrol yang menggunakan pembelajaran konvensional karena siswa senang mengikuti kegiatan belajar mengajar dipengaruhi adanya kegiatan ekperimen yang berbeda-beda disetiap pertemuannya. Kesempatan melakukan eksperimen diakui adalah hal pertama bagi peserta didik, karena sebelumnya diketahui belum pernah adanya kegiatan eksperimen. Hal ini merupakan salah satu daya tarik bagi siswa untuk belajar, ketika siswa merasa tertarik maka akan meningkatkan semangat siswa untuk mempersiapkan bahan, mengobservasi masalah, melaksanakan penyelidikan dan memberikan pendapat. Siswa juga merasa tertantang untuk mempresentasikan hasil penyelidikan di depan kelas serta memiliki daya saing tinggi dengan lawan kelompoknya.

Salah satu alternatif untuk meningkatkan hasil belajar dan aktivitas siswa adalah dengan 
menggunakan model PBL dalam pembelajaran. Hal ini sesuai dengan siswa yang tertarik dengan pembelajaran fisika karena melakukan eksperimen yang berbeda-beda dikarenakan belum pernah bereksperimen. Siswa juga merasa tertantang karena mempresentasikan hasil penyelidkan di depan kelas dan harus bersaing dengan kelompok yang lain. Situasi ini mendukung siswa untuk berpikir tingkat tinggi dan meningkatkan kreativitas siswa.

Hasil penelitian ini juga didukung oleh peneliti sebelumnya, diantaranya adalah (1) Necati Hirca (2011) menyatakan bahwa model PBL meningkatkan etika sebagai ilmuwan, berani menyatakan pendapat (saat proses), mendorong siswa untuk aktif dan meningkatkan daya tarik siswa. Guru juga semakin diingatkan untuk mengawasi siswa agar menemukan solusi sesuai dengan materi yang dibahas. (2) Gemze Sezgin Selçuk (2010). Hasil penelitian ini mengatakan bahwa belajar dengan menggunakan model PBL memberikan pengaruh positif, dibuktikan dengan efektivitas yang lebih jauh untuk mendorong minat siswa seperti daya tarik bagi siswa.

Tujuan dari siswa yang mempelajari model PBL adalah memberikan siswa dengan mereka percobaan sains dimana siswa dapat mendemonstrasikan prinsip-prinsip fisika. Guru yang mentransferkan ilmu dengan pendengar pasif tidak akan pernah sukses. Karena itu dengan model PBL akan membuat pelajar mengambil peran aktif dalam kegiatan belajar mengajar. Dengan cara menempatkan siswa pada pusat kegiatan belajar mengajar dalam pengawasan guru dengan penilaian yang objektif, sehingga pembelajaran lebih bermakna, (Necati, 2011).

Berdasarkan hasil data yang peneliti peroleh, peneliti sebelumnya dan kajian empirik (teori yang menjelaskan tentang model PBL), maka dapat disimpulkan bahwa penggunaan model PBL pada kelas eksperimen memberikan pengaruh yang signifikan terhadap hasil belajar siswa baik pada aspek pengetahuan, keterampilan, dan sikap serta aktivitas siswa. Aktivitas siswa semakin meningkat sejalan dengan fase-fase pada model PBL yang memiliki lima fase yatu, pertama memberikan orientasi permasalahan kepada peserta didik.

Berdasarkan terlaksananya model PBL, maka dapat diketahui fase yang paling menonjol adalah saat fase ketiga, yaitu pelaksanaan investigasi. Siswa antusias untuk melakukan penyelidikan untuk mengetahui solusi dari permasalahan yang diberikan. Penggunaan model PBL dapat meningkatkan hasil belajar baik dalam aspek pengetahuan, keterampilan, dan sikap serta aktivitas siswa, tetapi selama pembelajaran masih ada kendala yang dihadapi peneliti, yaitu waktu yang berkurang dikarenakan pemakaian pada jam pelajaran sebelumnya. Siswa yang masih bingung dengan masalah yang harus diselesaikan yang berkaitan dengan kehidupan sehari-hari dan materi yang terkait, sehingga siswa kurang terbiasa menganalogikan soal dalam bentuk masalah kemudian diorganisir pada aplikasi rumus. Rasa takut salah yang dimiliki siswa lebih dominan, sehingga setiap langkah percobaan harus ditanyakan dulu kepada peneliti dan ini menghabiskan waktu yang lama.

Kendala yang dihadapi peneliti adalah mencari masalah yang harus diselesaikan serta dekat dengan kehidupan sehari-hari untuk pelaksanaan praktikum disetiap pertemuan. Guru pengampu di kelas eksperimen sebelum mata pelajaran fisika memakai jam pelajaran fisika disetiappertemuannya hal ini mempengaruhi kegiatan belajar mengajar jam mata pelajaran fisika. Beda halnya dengan observer, observer mengalami kesulitan karena harus 
menilai tiga aspek sekaligus yaitu keterampilan, sikap dan aktivitas.

\section{KESIMPULAN DAN SARAN Kesimpulan}

Berdasarkan data yang diperoleh dari penelitian di kelas X MIA semester SMA Negeri 1 Stabat T.P. 2014/2015 dengan materi suhu dan kalor, dapat disimpulkan: (1) hasil belajar dengan menggunkaan model PBL memberikan nilai rata-rata pengetahuan pada kategori kurang baik, keterampilan dengan kategori baik sekali dan sikap dengan kategori baik. (2) Hasil belajar fisika dengan menggunakan pembelajaran konvensional memberikan nilai ratarata pengetahuan pada kategori tidak mencapai, keterampilan dengan kategori tidak mencapai dan sikap dengan kategori cukup baik. (3) Aktivitas siswa yang menggunkan model PBL termasuk kategori aktif, dan (4) ada perbedaan yang signifikan akibat pengaruh model PBL terhadap hasil belajar fisika siswa.

Saran

Kepada peneliti selanjutnya, perlu membuat perencanaan dengan sejelas-jelasnya terkhusus dalam pemilihan masalah yang akan digunakan dan tidak terlepas dengan materi dan khidupan sehari-hari, memaksimalakan kegiatan belajar dan bila perlu memperjelas waktu yang digunakan dengan pengajar pada jam sebelumnya, selama memulai kegiatan belejar perlu diperjelas tujuan pembelajaran sehingga solusi yang diberikan lebih terarah dan sesuaikan aspek yang ingin dinilai dengan jumlah observer.

Kepada guru mata pelajaran fisika disarankan menggunakan model PBL dalam pembelajaran sebagai salah satu alternative untuk meningkatkan hasil belajar siswa.

\section{DAFTAR PUSTAKA}

HIRÇA, N. (2011). Impact of ProblemBased Learning to Students and Teachers, Asia-Pacific Forum on Csience Learning and Teaching. Vol. 12, No. 7, hal. 1-19.

Selcuk, G.S. (2010). The Effects of Problem Based Learning on preservice teachers' achievement, approaches and attitudes towards learning physics. International Journal of the Physical Sciences.Vol. 5, No. 6, hal. 1.

Sudjana. (2009). Metode Statistika. Bandung: Tarsito.

Sugiyono. (2013). Metode Penelitian Pendidikan. Bandung: Alfabeta. 